\title{
Retrofit scenarios for emissions reduction in Italian hotels towards a Post-Carbon City
}

\author{
Giulia Crespi ${ }^{1}$, Cristina Becchio ${ }^{1}$, Stefano Paolo Corgnati ${ }^{1}$ \\ ${ }^{1}$ Department of Energy, Politecnico di Torino, Turin, Italy
}

\begin{abstract}
Nowadays there is an ever-increasing need for energy transition for moving towards a carbon-free economy and buildings play a crucial role in this process, targeted to reach a $90 \%$ reduction by 2050 . Zero-carbon building concept is taking hold, showing uncertainties and challenges in its achievement. The work focused on the issue of existing hotels, with the aim of investigating the possibility of achieving the ambitious zero-carbon targets. A reference hotel and different retrofit scenarios were simulated through EnergyPlus, in two Italian cities, Milan and Bari, evaluating the models with a multi-objective approach, in terms of comfort, energy and emissions reductions.
\end{abstract}

\section{Introduction}

Climate change is becoming apparent, arising growing concerns in the consciences of policymakers on the theme of greenhouse gas (GHG) emissions and their reduction in next years. The focus on a carbon neutral development has led national governments and international associations to define new concepts of sustainable city, often labelled as "low-carbon" or "Post-Carbon", aiming to reduce greenhouse gas emissions in all economic sectors and to make the development of economic activities and the environmental protection compatible (Nakata et al, 2011). From the viewpoint of a transition towards a carbon-free economy, buildings play a crucial role, due to their serious impact on the environment; buildings are responsible of approximately $40 \%$ of total final energy consumption and one third of global GHG emissions. These numbers highlight how this sector is at once one of the main causes of anthropogenic climate change and the economic sector with highest potentiality of energy and economic savings in the short-term, able to offer the most economically advantageous and easily applicable solutions. For this reason, European Commission has set ambitious targets of emissions reduction in the building sector, in order to reach a $90 \%$ cut for 2050 with respect to 1990 levels, as established by Roadmap 2050 (European Commission, 2012); this will be possible only thanks to the beneficial combination of demand reduction, energy efficiency and renewable energy integration actions (IPCC, 2007). What has been said so far underlines the view that the first step towards the actualization of a Post-Carbon City is the careful study of its composing elements and the achievement of buildings more and more efficient and sustainable. In this context, besides the well-known definition of nearly zeroenergy buildings (NZEB), introduced in the Energy Performance of Building Directive (EPBD) Recast (European Commission, 2010), the new concepts of lowcarbon or zero-carbon building are spreading, defined as buildings able to emit lower GHG emissions with respect to traditional ones. However, if from one side new constructions can (and must) be easily built as low-energy or low-carbon buildings thanks to the highly efficient technologies diffused in the market, on the other side the energy retrofit of existing buildings represent the biggest challenge of recent years. In this regard, the critical conditions of the existing building stock from an energy standpoint render it a sector rich of opportunities for savings, also considering that most of European countries experienced a housing boom between 1961 and 1990 and that $40 \%$ of buildings were built before 1960 , when the current energy efficiency requirements were not in force and just a part of this stock was subsequently retrofitted (BPIE, 2011). However, despite the saving potentialities enclosed in the existing stock, the theme of its requalification must be addressed with caution; indeed, the great variety of existing buildings, different in terms of periods of construction, size, location and typology of use, makes it hard to define a single approach to the problem. In this framework, non-residential buildings stand out as a challenging category to retrofit, varying significantly in terms of use, typology, and energy characteristics. As all the main economic sectors, tourism is surely not exempted from the European targets (European Commission, 2012), considering the remarkable impact it has on people lives and environment (Beccali et al, 2009). Indeed, hotels are among the most energy-consuming non-residential buildings, due to the energy-intensive provided services, the fluctuation in occupancy levels and the preferences in terms of thermal comfort, as well as their nonstop work (24/7). According to (HES, 2011), hotels rank fifth in the tertiary sector in terms of energy consumptions, lower only to commerce buildings, hospitals and offices. Furthermore, it was estimated that in 2005 the entire tourism sector contributed to $5 \%$ of global GHG emissions and that $20 \%$ of these were generated by hotels themselves (HES, 2011a). United Nations World Tourism Organization (UNWTO) appraised that, in a business-as-usual scenario, GHG emissions of the sector will increase of $+161 \%$ by 2035, with respect to 2005 levels (UNWTO, 2008). For this reason, actual tendency is to promote a sustainable 
tourism, as confirmed by the great amount of green labels, campaigns and initiatives (i.e. Nearly Zero Energy Hotel, NEZEH (2016), HES (2011b), etc.), spreading to increase people's awareness towards a not disruptive and ecofriendly kind of tourism. Energy savings opportunities are high in tourism sector, especially in cases where a considerable amount of energy is due to evitable wastes or bad managements (i.e. guests' low attention on thermostat control, non-controlled window opening, etc.). Thanks to the crucial role that hotel buildings plays in the definition of a Post-Carbon City, the paper aims to investigate the possibility of achieving the aforementioned low-carbon targets for hotel buildings, i.e. to achieve an hotel with the main scope of reducing its carbon emissions, without reducing the high-level comfort and services requested by guests. The zerocarbon theme appears complex and challenging at once and these difficulties are even more exacerbated for nonresidential buildings, whose stock is far less covered, due to the difficulties in tracking the existing stock of all different non-residential types. For non-residential buildings, thus, the concept of low carbon building appears to be less applied, due to energy consumptions not always easily reducible. Given the above considerations, the work aims firstly to extend the concept of low carbon building, so far addressed in literature mainly at residential level, to the hotel category. Then, the paper concerns the energy dynamic simulation (using EnergyPlus software) of a reference hotel, poorly efficient, and the modelling and simulation of different retrofit scenarios, both at system and envelope levels, for evaluating which measures are able to considerably reduce the building overall emissions. Analysis is based on the "whole building approach" (introduced in (European Commission, 2010)), meaning that, in case of retrofit, it is fundamental to find the right compromise between an envelope with good thermal performances and an efficient HVAC system configuration, which should be appropriate in function of climatic conditions. Indeed, it is globally recognized that external climatic conditions and envelope characteristics are among the factors that most influence energy consumptions. In this regard, since South Europe is characterized by extremely different climates, resulting in a great variety of scenarios, it happens often that a retrofit solution that results efficient in a city may not be the right one for another, even if geographically close. In the light of this, the study considered two Italian cities, Milan and Bari, characterized by different climatic condition, in order to verify how far these are able to influence the choice of the best technologies in terms of emissions reduction.

\section{Methods}

\section{Zero-carbon building definitions: review}

The complexity of the zero-carbon concept appears evident from the scarcity of information and norms, contributing to the absence of a definition globally approved and adopted. As affirmed by Pan (2014), the term zero-carbon building (ZCB) is slightly new, despite the research on low-energy and low-carbon buildings dates back to the 1940s. Whilst today the concept and assessment methodology of NZEB is known and clear, the ZCB concept experienced a low uptake since now (Pan, 2014). Nowadays, there exists several different terms and definition, which increase the complexity and misunderstanding on the topic. In (Pan, 2014), a careful literature review on some of the main definitions of $\mathrm{ZCB}$ was carried out. UK was the first country to introduce the $\mathrm{ZCB}$ in its policies; in particular, the UK definition of ZCB considers a building with null emissions over one year. In this regard, there is debate on which emissions should be accounted in the calculation, if only regulated emissions (emissions due to space heating, water heating, space cooling, ventilation and lighting) or complete emissions (also considering the non-regulated emissions, i.e. emissions due to cooking, washing and electrical equipment), being nowadays the first ones preferred (UK Government, 2010). Australian definition of ZCB again considers net null emissions over one year, and it depicts in general terms a ZCB as "a building that has no net annual Scope 1 (onsite emissions) and Scope 2 (from generation of electricity used in the buildings) emissions from the operation of building-incorporated services". However, the Australian Sustainable Built Environment Council (ASBEC, 2011) identified several definitions, different according to the system boundaries and scope of the analysis, among which two are relevant for the scope of the paper: zero carbon building and zero carbon occupied building. The first term accounts for only building emissions, meaning "emissions associated with the operation of building-incorporated services, as space heating and cooling, lighting, ventilation, cooking, washing, while the second term also includes the so-called occupant emissions, "associated with appliances and equipment brought into a building when it is occupied" (ASBEC, 2011). Finally, in US, there exists the definition of "Net Zero Energy Emissions", meaning a building that "produces at least as much emissions-free renewable energy as it uses from emissions-producing energy sources". This is the sole definition explicitly referring to renewable energy sources (RES), mainly onsite, needed to satisfy buildings energy demands (Pan, 2014).

It has to be noted that the majority of definitions so far introduced does not specify the building uses (residential and non-residential), not differentiating them in function of their energy behaviour. Nevertheless, despite the several definitions present worldwide, calculation methodology is clear only in the UK legislation, differently for residential and non-residential buildings. For the first category (Zero Carbon Hub, 2014), UK legislation provides maximum values of GHG emissions (i.e. carbon compliance), according to the typology of building (single-family house, terraced house and apartment block). For non-residential buildings, instead, the proposed approach (UK Government, 2006) is different, since a single requirement cannot be fixed for the whole sector, due to the evident differences among the different typologies within the sector. For this reason, UK legislation defines the compliance with zero-carbon targets in terms of percentage reductions of GHG 
emissions with respect to a reference building (with same shape and size of the analysed building) and it established three scenarios of decarbonisation: low, medium and high scenarios, aiming at $-44 \%,-49 \%$ and $-54 \%$ of emissions reduction, respectively (UK Government, 2006).

In conclusions, besides the lack of an explicit definition and calculation methodology, especially for nonresidential buildings, boundary conditions are often not clear; definitions in literature greatly vary in terms of accounted emissions, analysis periods and study boundaries. Moreover, in many cases, the sole on-site renewable energy generation is accounted for satisfying building needs, making it hard to reach the zero-carbon target for several building typologies. Under this article, different ZCB definitions were tested for non-residential buildings and for hotels, analysing the possibility of achieving the ZCB targets. UK calculation methodology for non-residential building was considered, to establish the zero-carbon targets. Moreover, three definitions were considered: 1) UK definition of zero carbon building (with only regulated emissions accounted); 2) Australian definition of zero carbon building; 3) Australian definition of zero carbon occupied building.

\section{Reference hotel model}

The building energy assessment was performed using the dynamic energy simulation software EnergyPlus (version 8.4). The study was developed using the reference building approach, each RB defined as a typical building considered representative of a portion of the building stock (Ballarini et al, 2014b). In particular, for the hotel case study, the RB was built starting from the model of "Large Hotel post 1980" defined by the US Department of Energy (DOE) and adjusting it in order to obtain the desired features (see Figure 1). The choice of the construction period was made in full acknowledgment of the evolution of Italian hotel facilities in the last decades (Federalberghi, 2014), choosing a hotel representative of the majority of hospitality buildings diffused in the period post 1980 in Italy. The selected RB is a seven-story hotel, with a net conditioned area of approximately 11'348 $\mathrm{m}^{2}$. The building has a rectangular plant, with the major façades North- and South-oriented; the window-to-wall ratio is $34 \%$. A lobby, a storage, a technical room, a laundry and a café for guests' exclusive use constitutes the ground floor (net conditioned area of 1'979 $\mathrm{m}^{2}$ ). Guestrooms and distribution areas occupy the intermediate floor (net conditioned area of 1'478 $\mathrm{m}^{2}$ ), while the last floor (net conditioned area of 1'478 $\mathrm{m}^{2}$ ) presents a kitchen, two breakfast rooms and a corridor, as well as guestrooms. Totally, the hotel presents 179 rooms, of which 161 with an area of $25 \mathrm{~m}^{2}$ and 18 of $39 \mathrm{~m}^{2}$. Finally, a conference room and a wellness centre constitute the underground floor (net conditioned area of 1'979 $\mathrm{m}^{2}$ ). All the construction typologies were derived from European project Typology for Building stock energy Assessment (TABULA) (Ballarini et al, 2014a), referring to 1976-1990 period of construction. Due to lack of data, identical thermal features were assumed for both locations. Materials properties are taken from (UNI EN ISO 10351, 1994; UNI EN ISO 11300-1, 2014). Internal heat sources, due to occupancy, lighting and electrical appliances, were set in compliance with regulations (UNI EN 15251, 2008; UNI 10339, 1995; ISO 18523-1, 2015), as well as the associate annual usage patterns.

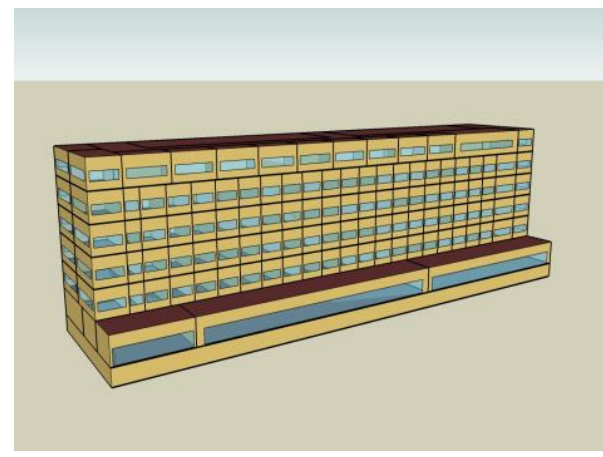

Figure 1: Reference hotel.

Typical climatic conditions were taken from DOE Weather for Energy Calculation Databases of Climatic Data. In compliance with Italian regulations (MiSE, 2015), heating and cooling seasons were set in accordance with the locations climatic zones. In Milan, belonging to climatic zone $\mathrm{E}$, heating season ranges from 15 th October to 15th April; in Bari, belonging to climatic zone $\mathrm{C}$, heating season ranges from 15th November to 31st March. Cooling seasons were set accordingly. The building was divided into 21 thermal zones, all conditioned with different schedules and operative temperature set-points, the latter being fixed according to comfort class I of UNI EN 15251 (2008). Table 1 summarizes set-points and set-backs of different thermal zones. Heating system operates only during the heating season, while cooling system is active during the whole year.

Table 1: Operative temperature set-points and set-backs and HVAC operational schedules.

\begin{tabular}{|c|c|c|c|}
\hline $\begin{array}{c}\text { Set-points } \\
\text { and schedule }\end{array}$ & Heating & Cooling & $\begin{array}{c}\text { Winter } \\
\text { cooling }\end{array}$ \\
\hline Guestrooms & $\begin{array}{c}21 / 15^{\circ} \mathrm{C} \\
18: 00-09: 00\end{array}$ & $\begin{array}{c}25.5 / 28^{\circ} \mathrm{C} \\
18: 00-09: 00\end{array}$ & $\begin{array}{c}25.5^{\circ} \mathrm{C} \\
18: 00-09: 00\end{array}$ \\
\hline Café & $\begin{array}{c}21^{\circ} \mathrm{C} \\
00: 00-24: 00\end{array}$ & $\begin{array}{c}25.5^{\circ} \mathrm{C} \\
00: 00-24: 00\end{array}$ & $\begin{array}{c}25.5^{\circ} \mathrm{C} \\
00: 00-24: 00\end{array}$ \\
\hline Breakfast & $21 / 15^{\circ} \mathrm{C}$ & $25.5^{\circ} \mathrm{C}$ & $25.5^{\circ} \mathrm{C}$ \\
rooms & $06: 00-11: 00$ & $06: 00-11: 00$ & $06: 00-11: 00$ \\
\hline \multirow{2}{*}{ Others } & $18^{\circ} \mathrm{C}$ & $25.5^{\circ} \mathrm{C}$ & $25.5^{\circ} \mathrm{C}$ \\
& $00: 00-24: 00$ & $00: 00-24: 00$ & $00: 00-24: 00$ \\
\hline
\end{tabular}

The reference hotel technical system was modelled in accordance with (Winiarski et al, 2006). Space and water heating are provided by a natural gas boiler, with a theoretical efficiency of $88 \%$, and space cooling by a water-cooled chiller with a 3 EER. Heating terminals are different in the modelled thermal zones. Specifically, in guestrooms, four-pipe fan coils were modelled, realizing a double circuit for hot and chilled water, allowing their simultaneous delivery in different rooms. Variable air volume (VAV) systems with zonal post-heating were installed in the remaining thermal zones, in order to respond contemporary to different needs. In particular, three separate air-handling units (the former serving kitchen and laundry, the second one providing air to the 
sole conference room and the latter serving the remaining zones) provide a centralized handling, delivering air with equal temperature and relative humidity characteristics; a zonal post-heating battery performs the final air postheating, allowing a local control.

\section{Retrofit scenarios}

Different retrofit measures were defined and simulated using EnergyPlus software. The same hypotheses were applied for the hotels located in Milan and Bari, in order to verify the effect of climate, aiming at identifying the retrofit measures able to guarantee highest emission reductions. Retrofit measures were divided into Envelope Retrofit Measures (ERM) and System Retrofit Measures (SRM). ERM_1 considers the addition of an external coating insulation layer of Sintered Polystyrene Foam on external walls and roof, with specific thickness values in the diverse considered locations, to obtain U-values in compliance with the Italian legislation requirements for the climatic zones (MiSE, 2012). ERM_2 consists in windows replacement, always aiming at satisfying minimum requirements. Table 2 gives a bird's eye on the new thermal features introduced by ERM_1 and ERM_2, compared to those of the reference hotel.

Table 2: Thermal features of main external envelope components, reference hotel and law requirements.

\begin{tabular}{|c|c|c|c|}
\hline U-values [W/m² $\mathbf{K}]$ & Reference Hotel & Milan & Bari \\
\hline External wall & 0.76 & 0.30 & 0.37 \\
\hline Roof & 0.75 & 0.25 & 0.34 \\
\hline Window & 3.7 & 1.8 & 2.4 \\
\hline
\end{tabular}

Furthermore, on the technical side, eight SRMs were defined.SRM_1 considers the substitution of the installed lighting systems with LED technology in all the thermal zones. SRM_2 assumes the installation of VAV in guestrooms (substituting the existing fan coils), the installation of cross-flow plate heat recovery units in the AHUs and the substitution of boiler and chiller with better-performing ones (efficiency of 0.92 and 3.5, respectively). SRM_3 and SRM_4 options consider the adoption of renewable energy technologies, considering different mix of PV panels and solar collectors. Specifically, SRM_3 considers the installation of both PV panels and solar collectors on available surfaces, while SRM_4 considers the adoption of sole PV. SRM_5 evaluates the hotel connection to a district heating network. Finally, SRM_6, SRM_7 and SRM_8 consider the substitution of the original natural gas boiler with other heating systems, condensing gas boiler (theoretical efficiency equal to 0.95), an electrical boiler (theoretical efficiency of 0.95) and air-to-water heat pump (COP of 4), respectively. All these measures were combined into different packages, obtaining two Envelope Retrofit Packages (ERP), for Milan and Bari respectively (including both ERM_1 and ERM_2 at once), and seven System Retrofit Packages (SRP), equally implemented for the hotels in both locations (see Table 3).

Table 3: Definition of System Retrofit Packages (SRPs).

\begin{tabular}{|l|l|}
\hline & SRMs in different SRPs \\
\hline SRP_1 & SRM_1 \\
\hline
\end{tabular}

\begin{tabular}{|l|l|}
\hline SRP_2 & SRM_1 + SRM_2 \\
\hline SRP_3 & SRM_1 + SRM_2 +SRM_3 \\
\hline SRP_4 & SRM_1 + SRM_2 +SRM_3 + SRM_5 \\
\hline SRP_5 & SRM_1 + SRM_2 +SRM_3 + SRM_6 \\
\hline SRP_6 & SRM_1 + SRM_2 +SRM_4 + SRM_7 \\
\hline SRP_7 & SRM_1 + SRM_2 +SRM_4 + SRM_8 \\
\hline
\end{tabular}

Finally, starting from the reference hotels (M0 and B0, for Milan and Bari respectively), two scenarios were defined, based on different combinations of envelope measures, building technical systems and on-site renewable energy sources. The former (scenario 1) assumes not to intervene on the envelope, presuming to act on the sole technical systems and applying the seven SRPs (obtaining seven scenarios for Milan and seven scenarios for Bari). The latter (scenario 2) considers intervening on both envelope and technical sides, combining SRPs with the ERPs, needed to satisfy Italian U-value law requirements (obtaining seven scenarios for Milan and seven scenarios for Bari). Finally, to consider the effect of the sole envelope retrofit, two models were simulated (M0_law and B0_law, for Milan and Bari, respectively), which consider the application of ERPs on the reference hotels (M0 and B0), without acting on HVAC systems. Each model is identified by a code, in which the letter identifies the location ( $M$ for Milan and B for Bari), the number the system package implemented. In addition, since the second scenario aims to satisfy the U-value law requirements, the code of each model is followed by "law". In conclusion, 2 reference hotels and 30 retrofit scenarios were totally modelled, with detailed sub-hourly simulations and obtaining results on annual basis.

\section{Results and discussion}

Energy efficiency, carbon emissions and thermal comfort analysis are essential elements to consider when approaching the design of zero carbon buildings. The 32 simulated models were assessed with a multi-objective approach, evaluating thermal comfort, energy consumptions, and GHG emissions, in absolute values and in percentage terms with respect to reference models. The main scope was to compare the energy behaviour of the different retrofitted hotels and to visualize the retrofit scenarios able to guarantee higher GHG reductions, in the two selected climates, without affecting guests' thermal comfort. In this regard, for all simulated hotels, thermal comfort was monitored in terms of Predicted Mean Vote (PMV), indicator defined by Fanger as the mean vote of thermal sensation on a -3 to +3 scale, where 0 corresponds to the thermal neutrality condition. UNI EN 15251 (2008) identifies four comfort classes (from I to IV), related to different ranges of PMV (Class I: $-0.3<\mathrm{PMV}<0.3$; Class II: $-0.5<$ PMV $<0.5$; Class III: $-0.7<\mathrm{PMV}<0.7$; Class IV: PMV $>0.7$ ), where Class II corresponds to the condition of thermal neutrality. UNI EN 15251 established that the assessment of thermal comfort based on PMV should be done in thermal zones were occupants spend most of the time and thus calculations were carried out for the rooms. The analysis aimed to evaluate if the different retrofit scenarios are able to guarantee appropriate conditions of 
thermal comfort (Classes I and II) in the rooms during occupancy hours (5475 out of 8760 hour in one year). Figure 2 presents the analysis for Milan and for the Southoriented rooms. It appears that, during the occupancy period, for all the retrofit scenarios, for approximately $90 \%$ of the time PMV belongs to Classes I and II. The same analysis was carried out for North-oriented rooms and for Bari as well. Generally, despite a better behaviour in South-oriented rooms in both location, due to higher solar exposure, obtained results were positive, showing high level of thermal comfort for the majority of the occupancy hours in all scenarios and locations. Other things being equal, it was possible to note that comparing the same retrofit scenarios, with and without envelope retrofit, it was possible to observe that the percentages of Classes I and II increase, showing slightly better thermal comfort conditions for the "law" models.

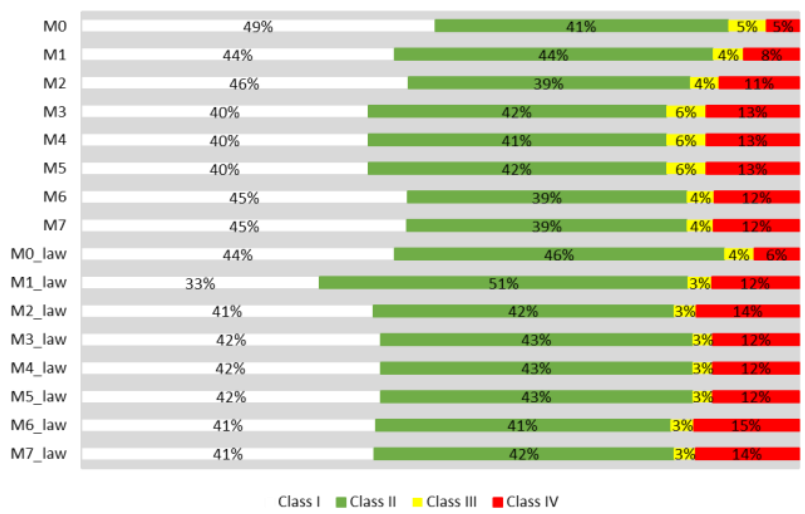

Figure 2: PMV distribution in UNI EN 15251 Classes for South-oriented rooms, Milan hotels.

However, the focus of the analysis was obviously that of comparing the GHG emissions generated by the different simulated models, especially in order to evaluate their capability in achieving the zero-carbon targets defined for the study. Energy-related emissions were calculated using the emissions factors defined in (ISO 52000-1, 2015) for different energy carriers. Based on the UK calculation methodology, three emission reduction targets were defined (low scenario $-44 \%$, medium scenario $-49 \%$, high scenario -54\%). These values were compared to the percentage reductions of simulated models calculated with respect to the emission levels of the reference hotels (M0 and B0). The research considered the three ZCB definitions previously defined: the UK zero-carbon building (case I), the Australian zero-carbon building (case II) and zero-carbon occupied building (case III) definitions. Graphs in Figures 2 represent, for the hotels located in Bari (Figure 3a) and Milan (Figure 3b) respectively, the GHG emission reductions in the different models, calculated with respect to the reference hotels. The horizontal lines represent the zero-carbon targets, fixed by UK Government (2006). Two fundamental results come out. Firstly, the role of electrical equipment in the GHG emissions accounting appears to be significantly relevant, justified by the difference between emission reductions for case I (green) and case II (yellow). Moreover, both graphs highlight the difficulty in achieving the three targets; it appears clearly that only in case occupant emissions are not accounted (totally, case I or partially, case II) it is possible to achieve at least one of the defined targets.

Due to the effect of electrical equipment using in the overall carbon footprint of the simulated hotels (which account for approximately $30 \%$ of total GHG emissions), the Australian definition of zero carbon occupied building (case III, in yellow) seems to be the most comprehensive for this research, able to account also for occupant behaviour aspects.

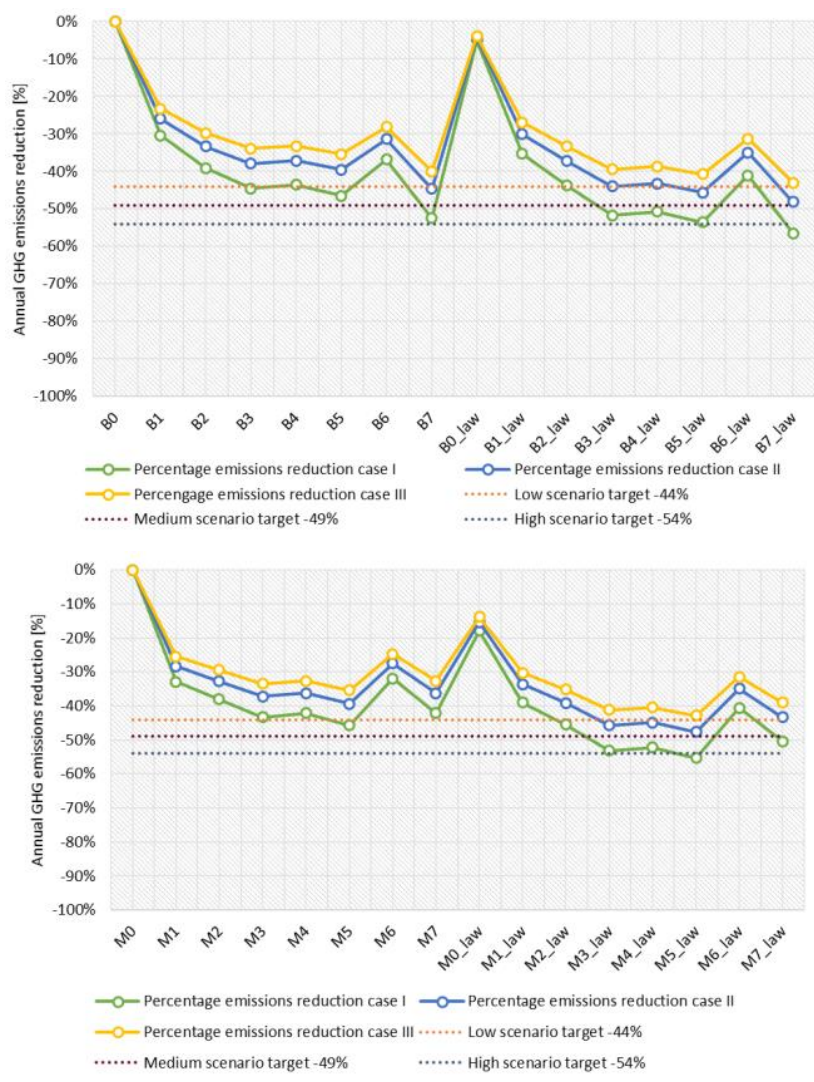

Figure 3: Annual GHG emissions reduction and zerocarbon targets, Bari above (2a) and Milan below (2b).

The graphs in Figure 4 are built according to the Australian definition (case III), showing the retrofit scenarios ordered for decreasing emissions, in order to investigate the best solutions for the hotels located in Bari and Milan. Figure 4 reveals two important elements. Firstly, the differences between Milan and Bari show how climate can strongly influence the choice of the best retrofit scenario for a certain location. Indeed, best solutions in the two Italian cities are different; in Bari (Figure 4a), B7_law (combination of envelope measures and installation of an electric heat pump) guarantees the highest GHG emissions reduction (-43\%), since in South Italy heat pump benefits from higher external temperature in winter season. Next up, condensing gas boiler (B5_law) and heat pump without envelope retrofit (B7) can be found, guaranteeing $-41 \%$ and $-40 \%$ emissions reduction, respectively. As for Milan (Figure 4b), instead, models with highest GHG reductions are those still using gas as main energy carrier for space and water heating; 
indeed, for Milan, higher GHG emission reductions can be found for M5_law (-43\%), M3_law (-41\%), and M4_law (-40\%), all characterized by higher levels of envelope insulation and by condensing gas boiler, traditional gas boiler and district heating as technological options, respectively.
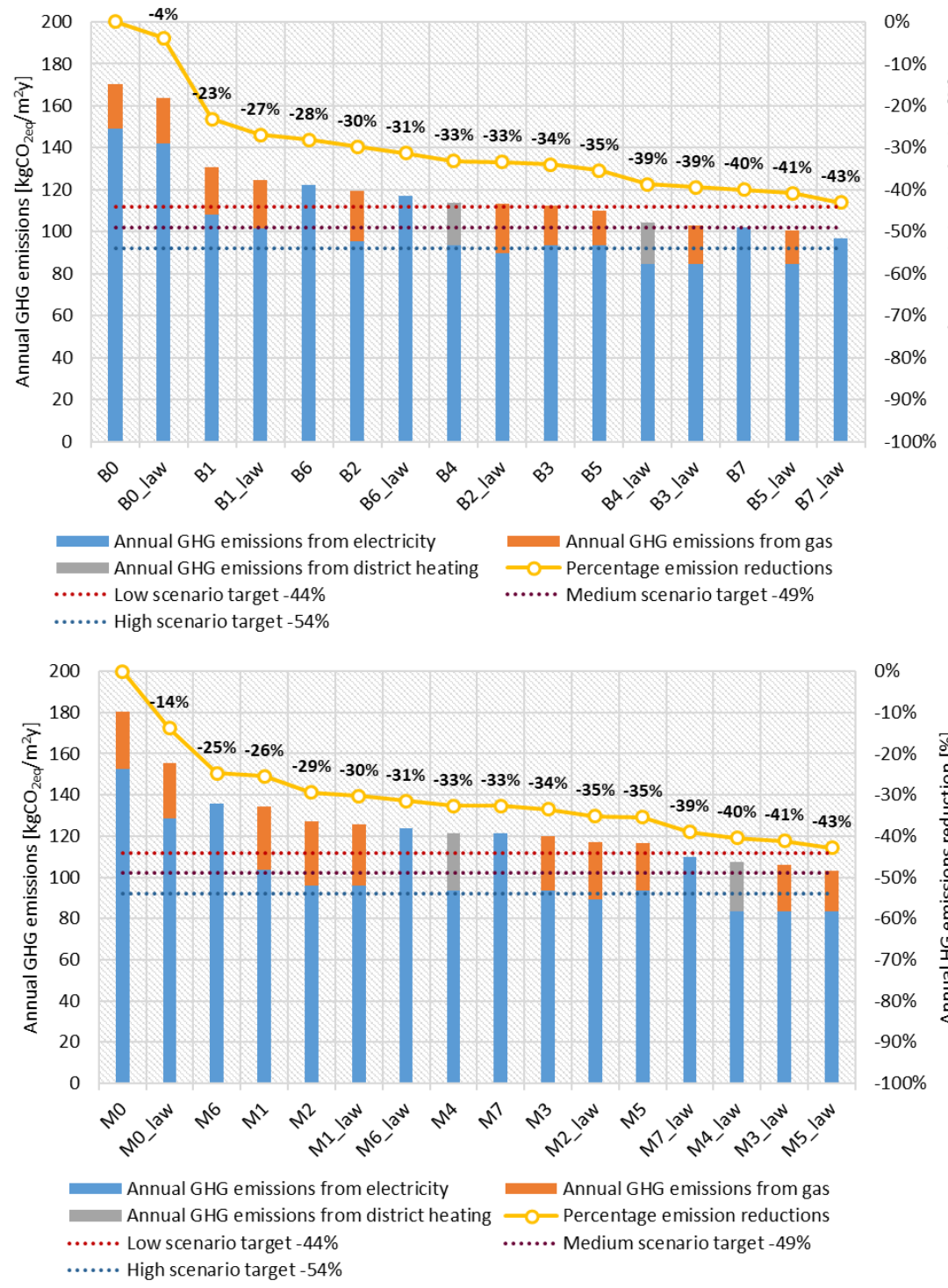

Figure 4: GHG emissions, zero carbon occupied building (case III), Bari above (4a) and Milan below (4b).

As expected, moreover, insulation effect is stronger in cold climates. In Milan (Figure 4b), the sole envelope retrofit scenario (M0_law) guarantees an emission reduction of $-14 \%$, opposed to the $-4 \%$ obtained in Bari (B0_law). Even though M0 and B0 present identical thermal features (in terms of U-values), M0_law and B0_law were built according to the minimum requirements defined by current legislation (MiSE, 2015) and fixed differently according to the belonging climatic zones. In particular, in Milan (climatic zone E), U-values requirements are higher with respect to Bari (climatic zone $\mathrm{C}$ ), justifying the obtained results.

According to (European Commission, 2010), each building, either new or existent, should be studied as a complex system based on a whole building approach. In particular, in order to obtain a highly efficient building and thus to minimize its consumptions, acting solely on envelope by increasing insulation levels is not always profitable. On the contrary, it is fundamental to find the best compromise between envelopes with good thermal performances and efficient technological options, appropriate for the single cases, in function of climatic conditions. Figure 4 underlines this aspect, showing that the best scenarios in terms of GHG emission reductions, for both Milan and Bari, present both efficient technological solutions and high insulation.

Finally, ZCB concept is strictly linked to the deployment of renewable energy sources (RES). Simulation results highlight how best performing scenarios are the ones considering the installation of RES to partially match hotel consumptions. Nevertheless, the unbalance between RES production and hotel energy demands appears clear. Constraints related to location and building typology (i.e. presence of solar shadings, lack of sufficient space for installation of RES, etc.) make it hard to achieve the zerocarbon targets for all buildings, and especially for existing 
ones, for which the installation of RES is often restricted by technical feasibility and cost issues. Moreover, it has to be considered that non-residential buildings consume higher amounts of energy and resources. To graphically represent these considerations, an indicator was defined to better explain the distance of the simulated hotels to the theoretical targets of null emissions; in particular, the indicator is calculated as the missing surface of RES technologies needed in order to annul the difference between the hotels energy consumption and the relative onsite RES production. Always based on zero-carbon occupied building definition (case III), Figures 5-7 focus on Milan hotels and on the sole electricity consumption of the simulated hotels. Figure 5 shows the percentages of missing PV surface needed in order to counterbalance PV production and hotel electricity consumption, highlighting the strong mismatch between onsite generation and consumption.

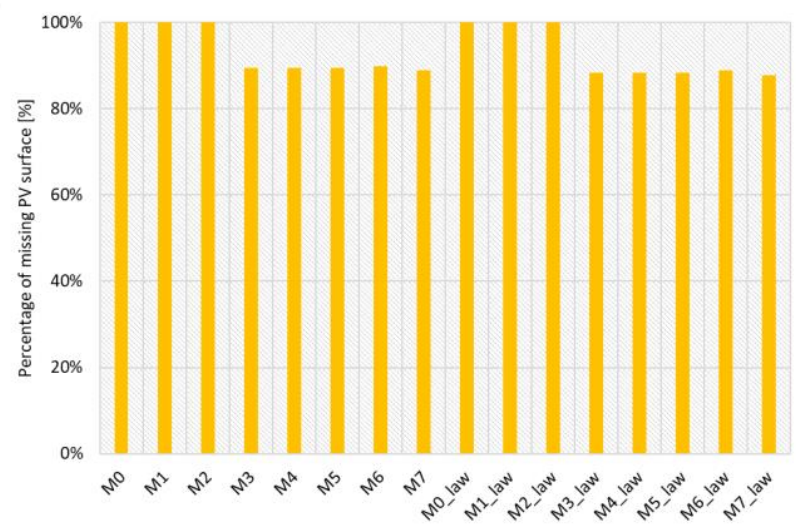

Figure 5: Percentages of missing PV surface, case III, Milan hotels.

The analysis was further extended, assuming to have at disposal a parking area close to the hotel, whose roof was covered of PV panels. Figure 6 shows the reduction of the percentages of missing PV surfaces, but still the gap appears considerable. However, these considerations take into account the Australian definition of zero-carbon occupied building (case III), for which it is difficult to reach the zero-carbon targets defined by UK legislation (Figure 3).

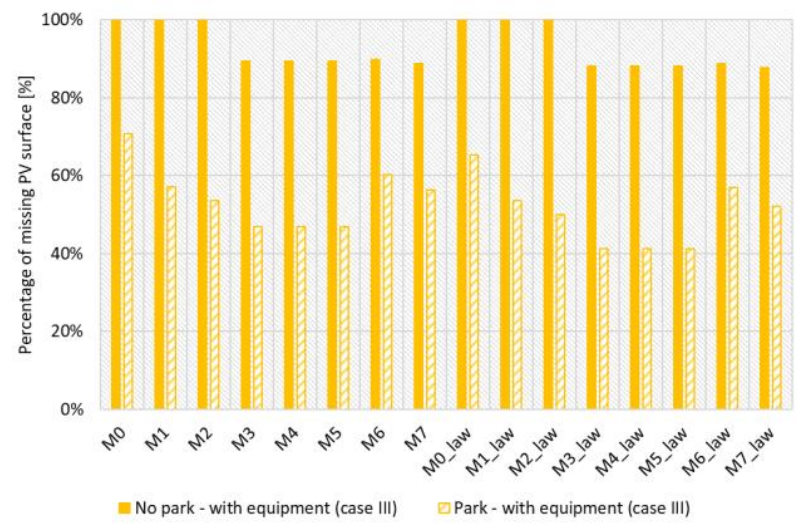

Figure 6: Percentages of missing PV surface, solutions without and with parking area, case III, Milan hotels.
To explore the effect of the choice of ZCB definition, the analysis of the indicator was carried out also for the UK definition of zero-carbon building (case I). Figure 7 reports the percentages of missing surfaces for case I, showing that the addition of PV panels on the parking area can help in reaching the carbon neutrality in some simulated hotels. Particularly, it appears that the retrofit scenarios with RES installations already in place and with no electrical heating systems (M3_law, M4_law, M5_law) are able to reach the carbon neutrality, on an annual basis.

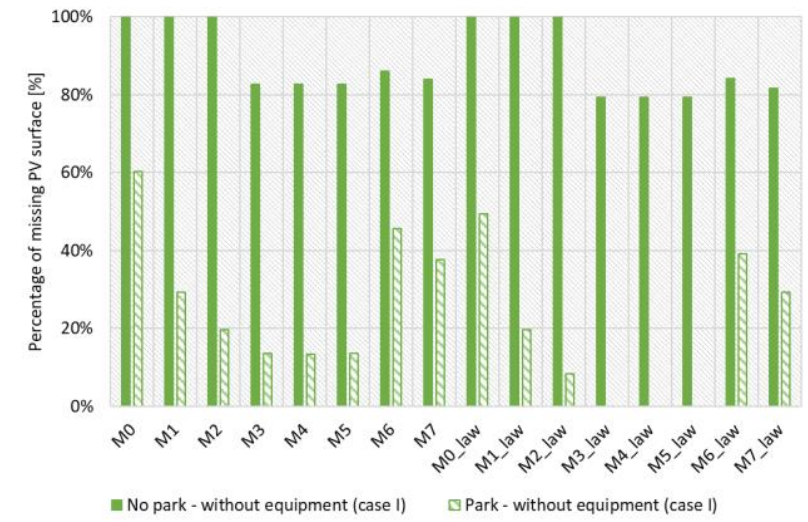

Figure 7: Percentages of missing PV surface, solutions without and with parking area, case I, Milan hotels.

\section{Conclusion}

Concentrating on the energy retrofit of a hotel building, the paper consists in the energy-dynamic simulation of different retrofit scenarios, at HVAC system or/and envelope levels, in order to evaluate the possibility of achieving the ambitious zero-carbon target for the analysed building typology. The obtained results allowed to conclude that the apparent difference between residential and non-residential buildings, in terms of offered services, and mainly of energy demands and consumptions, does not permit to identify a single zerocarbon target, asking for more differentiated and accurate definitions and norms, scaled for the different building typologies and uses. The ZCB definitions used in this research paper, resulting from a literature review on the concept, limit their analysis at building scale; however, it appears clear that, to reduce buildings carbon footprints, it is crucial to consider its interaction with surrounding environment (district or city scale). The obtained results, indeed, highlighted the need to find a ZCB definition that can fit better into the wide concept of Post-Carbon city. In this sense, it is necessary to extend the study boundaries, accepting that the buildings energy demand could be matched not only using onsite, but also offsite RES production. That seems to be the only way to extend the ZCB definition to all building typologies, new and existent, residential and non-residential, including those with constraints for onsite RES installation.

This paper provides some interesting stimuli for future works; in the view of Post-Carbon city, project processes at building and district levels should be intimately linked. Buildings should be figured not as single entities, but as interconnected elements inserted into a larger-scale 
energy system, in which RES and storage systems are installed so that to share and exchange energy, in function of real demands. Future objectives at district or city level foresee the creation of bi-directional smart grids and the development of smart technologies and systems able to increase demand flexibility, actually responding to the need of distributed generation and local RES. Furthermore, an increasingly number of cities are creating thermal networks (i.e. district heating, low temperature networks, etc.) with the aim of decentralizing energy production, in order to reduce overall GHG emissions in cities. Post-Carbon concept consists in a real re-think of urban space and of its energy systems and it represents a challenging project, representing a possible pathway towards the needed energy transition and the ambitious future targets of GHG emissions reduction.

\section{References}

Australian Sustainable Built Environment Council, ASBEC (2011). Defining zero emission buildings Review and recommendations: Final Report.

Ballarini, I., Corgnati, S.P., Corrado, V. (2014a). Building Typology Brochure - Italy, Episcope, TABULA.

Ballarini, I., Corgnati, S.P., Corrado, V. (2014b). Use of reference buildings to assess the energy savings potentials of the residential building stock: the experience of TABULA project. Energy Policy 68, 273-284.

Beccali, M., La Gennusa, L., Lo Coco, L., Rizzo, G. (2009). An empirical approach for ranking environmental and energy saving measures in the hotel sector. Renewable Energy 34, 82-90.

Building Performance Institute Europe, BPIE (2011). Europe's Buildings under the Microscope.

Department for Communities and Local Government (2011). Zero carbon non-domestic buildings, Phase 3 final report.

Ente nazionale italiano di unificazione (2008). Criteri per la progettazione dell'ambiente interno e per la valutazione della prestazione energetica degli edifici, in relazione alla quantità di aria interna, all'ambiente termico, all'illuminazione e all'acustica (UNI EN 15251).

Ente nazionale italiano di unificazione (1994). Materiali e prodotti per edilizia - Proprietà termoigrometriche - Procedura per la scelta dei valori di progetto (UNI EN ISO 10351).

Ente nazionale italiano di unificazione (1995). Impianti aeraulici a fini di benessere: Generalità, classificazione e requisiti, Regole per la richiesta d'offerta, l'offerta, l'ordine e la fornitura (UNI 10339).

Ente nazionale italiano di unificazione (2014). Prestazioni energetiche degli edifici. Parte I: Determinazione del fabbisogno di energia termica dell'edificio per la climatizzazione estiva ed invernale (UNI EN ISO 11300-1).
European Commission (2010). Directive 20/31/EC of the European Parliament and of the Council of 19 May 2010 on the energy performance of buildings (recast).

European Commission (2012). Roadmap for moving to a competitive low-carbon economy in 2050.

Federalberghi (2014). Settimo rapporto su sistema alberghiero e turistico ricettivo in Italia.

Hotel Energy Solutions, HES (2011a). Analysis on energy use by European hotels: online survey and desk research.

Hotel Energy Solutions, HES (2011b). Hotel Energy Solutions: Fostering innovation to fight climate change.

Intergovernmental Panel on Climate Change, IPCC (2007). Climate change 2007: Working Group III: Mitigation of Climate Change.

International Organisation for Standardisation (2015). Energy performance of buildings - Schedule and condition of building, zone and room usage for energy calculation - Part 1: Non-residential buildings (ISO 18523-1).

International Organisation for Standardisation (2015). nergy Performance of Buildings - Overarching EPB assessment (ISO 52000-1).

Ministero dello Sviluppo Economico, MiSE (2015). Decreto ministeriale 26 giugno 2015 - Adeguamento linee guida nazionali per la certificazione energetica degli edifici.

Nakata, T., Silva, D., Rodionov, M. (2011). Application of energy system models for designing a low-carbon society. Progress in Energy and Combustion Science 37, 462-502.

Nearly Zero Energy Hotels, neZEH (2016). Nearly Zero Energy Hotels in Europe, Flagship projects and tools for hoteliers.

Pan, W. (2014). System boundaries of zero carbon buildings. Renewable and Sustainable Energy Reviews 37, 424-434.

POCACITO (2014). Report on Key Performance Indicators.

United Nations World Tourism Organization, UNWTO (2008). Climate Change and Tourism: Responding to Global Challenges.

UK government (2006). Part L 2006: Conservation of fuel and power.

UK government (2010). Part L 2010: Conservation of fuel and power in existing buildings.

Winiarski, D.W., Jiang, W., Halverson, M.A. (2006). Review of Pre- and Post-1980 Buildings in CBECS HVAC Equipment.

Zero Carbon Hub (2014). Zero Carbon Homes and Nearly Zero Energy Buildings, UK Building Regulations and EU Directives. 